\title{
LA INFLUENCIA DE LA IDEOLOGÍA AUGUSTEA EN LA DECORACIÓN DE POMPEYA Y HERCULANO
}

\author{
UMBERTO PAPPALARDO * \\ Istituto Universitario \\ "Suor Orsola Benincasa"
}

\begin{abstract}
Herculano y Pompeya, buenos exponentes de las ciudades itálicas y provinciales, y mejor conservadas, nos ilustran, como se observa en los ejemplos aquí analizados, sobre el cambio de régimen político en Roma en la época de Augusto, con sus nuevos gustos culturales, expresión de la ideologia triunfante, de las virtutes del líder emergente.

Serán las familias más influyentes y los parvenues quienes se identifiquen mejor con el programa cultural y con la ideología del princeps, y actuarán de transmisores de los nuevos valores a sus propios conciudadanos, como en los casos de M. Nonius Balbus en Herculano, y $M$. Holconius Rufus y Eumachia en Pompeya. Esto es lo que se trasluce al examinar el programa decorativo de las Termas Suburbanas y del Colegio de los Augustales en Herculano, así como en el edificio de Eumachia y el Templo de Vespasiano en Pompeya.
\end{abstract}

Herculaneum and Pompeii, well-preserved typical Italic provincial cities, demonstrate, as we can observe in the examples analysed here, the change of political regime in Rome during the Augustan period, with its new cultural tastes, expression of a triumphant ideology, the virtues of the new leader.

It would have been the most influential families and the parvenus who identified themselves most closely with the cultural preferences and ideology of the princeps, and who transmitted the new values to their fellow citizens, as in the case of $M$. Nonius Balbus in Herculaneum and M. Holconius Rufus and Eumachia in Pompeii. This can be discerned in the decor of the Suburban Baths and the College of the Augustales in Herculaneum, or the Eumachia building and the Temple of Vespasian in Pompeii.

Desde el momento en que fueron descubiertas en el siglo XVIII, Pompeya y Herculano, que en la Antigüedad eran sólo acomodadas ciudades de provincia, se convirtieron en una inagotable fuente de información sobre la historia del mundo romano. El estudio de este mundo y la reflexión sobre la función de su producción artística también nos permite comprender mejor algunos aspectos estructurales de nuestra civilización occidental, por ejemplo, la formación del retrato como autocelebración burguesa (AA.VV., 1980; Zanker, 1982, 307312, figs. 197-209), la importancia de la poesía amorosa de Catulo y Ovidio en la expresión actual de nuestros sentimientos (Fedeli, 1991) y también el reflejo de una ideología política en la elección de los adornos, en aquellos casos en que los propietarios quieren manifestar su adhesión a esa ideología (Zanker, 1993).
Artífices de esta adhesión a los programas políticos augusteos son, en Herculano, personajes como Marco Nonio Balbo y, en Pompeya, personajes tales como Marco Olconio Rufo y Eumachia. Esto es lo que se trasluce al examinar el programa decorativo de las Termas Suburbanas y del Colegio de los Augustales en Herculano, así como en el Edificio de Eumachia y el Templo de Vespasiano en Pompeya.

Después del caos de fines de la república, luego de décadas de guerras civiles, de proscripciones, exterminios y apropiaciones, la "pax augusta" traía, junto con la seguridad, un gran renacimiento económico (Rostovtzev, 1981). En otras ciudades itálicas, así como en

\footnotetext{
* Actual Director de Excavaciones. Prof. of Pompeian Archaeology.E-mail: umbpappa@/ibero.it
} 


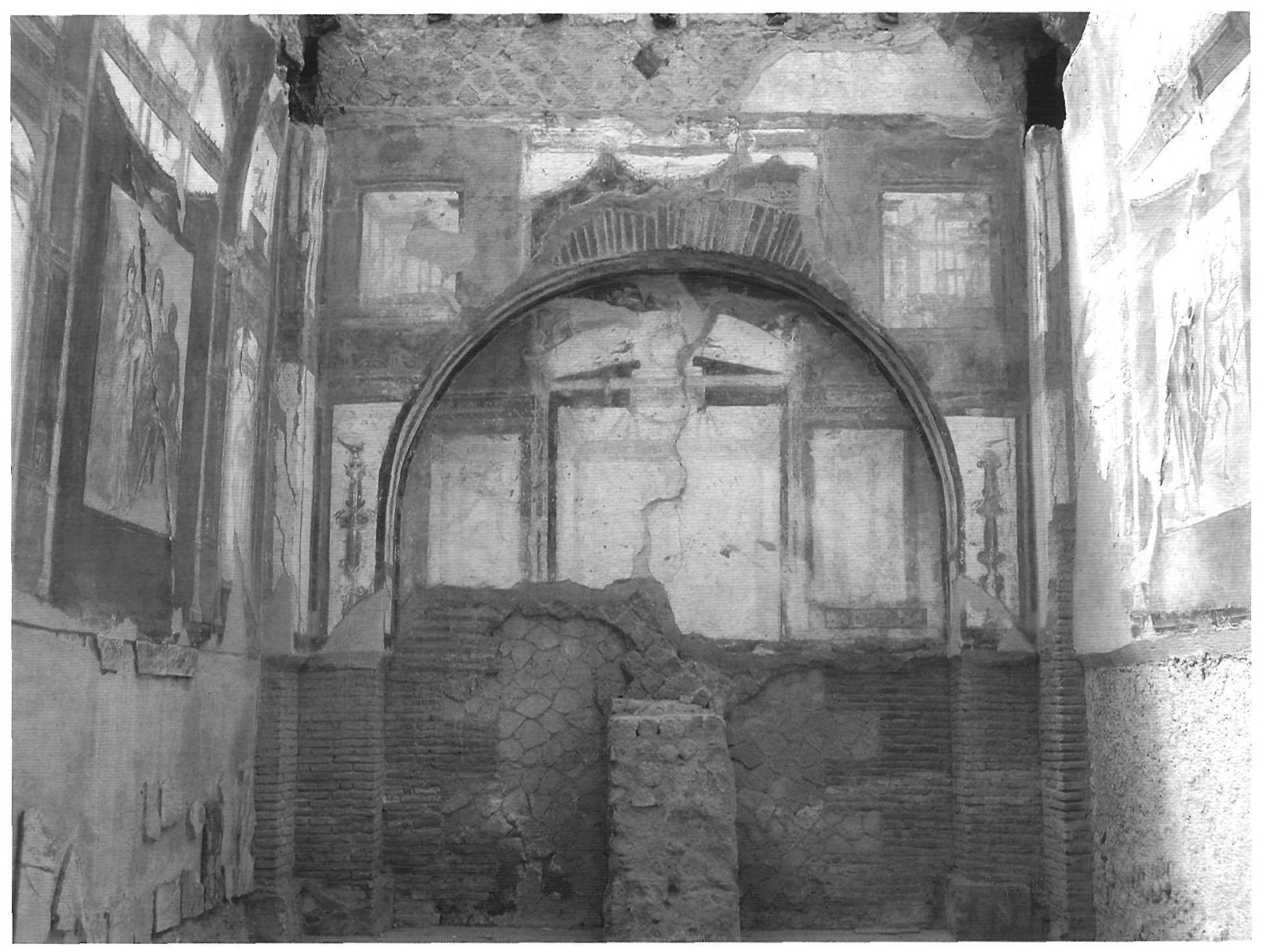

Figura 1: Herculano, Aedes Augustalium, cella.

los casos puntuales de Pompeya y Herculano, son las familias más influyentes y los "parvenus" quienes se identificaban con el programa cultural del nuevo régimen y quienes transmitían a sus conciudadanos el modelo del "princeps", como un ejemplo a imitar ${ }^{-1}$.

\section{EL COLEGIO DE LOS AUGUSTALES EN HERCULANO}

El Colegio de los Augustales es uno de los edificios más sugestivos de Herculano. Fue construido en el área de la ciudad dedicada a los edificios públicos ${ }^{2}$.

Los "augustales" eran los adeptos al culto imperial, reunidos en un colegio sacro. Aquellos que no podian tener acceso a la magistratura, sobretodo los libertos, encontraban en estos colegios un instrumento de "escalation" social, puesto que con la concesión de la "augustalitas" quedaban colocados en una posición intermedia entre la "plebs" y el "ordo decurionum" (Duthoy, 1978, 1254-1309). En Herculano se conserva el registro en mármol de los Augustales, el cual nos da los nombres de los "augustales" de la última década de vida de la ciudad; los nombres están agrupados por clase de libres ("Centuria Claudia ingenuorum") y libertos ("Centuria Veneria" y "Centuria Concordia") (Guadagno, 1977, 114-122; idem, 1988, 199-203).

El edificio, de fines de la época augustea, es un cubo de dos plantas. En la planta baja se ubica la gran sala hipóstila, pintada de blanco, para las reuniones públicas. Por medio de una escalera externa, se subía al matroneo, desde donde se podía asistir a lo que se desarrollaba en la planta baja, a través de cuatro amplias ventanas. La pared del fondo de la gran sala está casi en su totalidad ocupada por una amplia cella, destacada respecto a la sala y suntuosamente decorada, con piso y zócalo revestidos con placas de mármol y paredes pintadas

\footnotetext{
1 Estudios fundamentales : Zanker, 1987; Zanker, 1991, 193220; Zanker, 1993.

2 Sobre el Colegio de los Augustales de Herculano: Andreae, 1973, Fig. 75-76; Guadagno, 1983, 159-173; Moormann, 1983, 175-177; Etienne, 1993, 345-350. Sobre las pinturas: Pappalardo, 1993a, Vol. I, Lám. A Col. 144-146; Vol. II, Nr. 437-440; Pappalardo, 1993b, 90-95, Fig. 1-9, Lám.1, 4.
} 
en época vespasiana (el llamado cuarto estilo) (Fig. 1). Una inscripción mármorea recuerda:

\author{
AVGVSTÓ · SACR (um) \\ A(ulus) $\cdot$ A(ulus) · LVCII A(uli) FILII - MEN (enia) \\ PROCVLUS - ET - IVLIANVS \\ $P$ (ecunia) $\cdot S($ ua) \\ DÉDICÁTIÓNE · DECVRIÓNIBUS · ET \\ AVGVSTÁLIBUS - CÉNAM DEDÉRVNT
}

"Consagrado a Augusto. Aulo Lucio Proculo y Aulo Lucio luliano, hijos de Aulo, de la tribu Menenia, ofrecen por su propia cuenta un banquete a los decuriones y augustales en ocasión de la consagración (del edificio)".

Es interesante notar la presencia de "ápi$\operatorname{ces}^{3}$ y la tendencia a la acentuación métrica, que al menos en las dos últimos renglones, es similar a la del endecasílabo sáfico, empleado por Horacio para el "Carmen Saeculare" (Norberg, 1946, 389ss). No se debe descartar la idea de que la estrofa haya formado parte del himno cantado durante la cena ofrecida para la inauguración del edificio.

Sobre la pared del fondo de la cella, se ubica un pedestal destinado a sostener el busto del emperador. También, dos pedestales adosados a las columnas anteriores de la sala, sostenian estatuas dedicadas al "divo lulio" y al "divo Augusto", como lo muestran, ya solamente, las inscripciones.

En las paredes laterales de la cella, hay pintados dos cuadros, uno sobre "Hércules y Aqueloo" y el otro con "La apoteósis de Hércules". Lateralmente a los cuadros, hay pintados dos escorzos perspécticos: en alto aparecen bigas guiadas por Victorias y en la parte baja, en las predelas, vasos y palmas como premios agonales.

El cuadro con "Hércules y Aqueloo" representa al héroe luchando con Aqueloo quien ha intentado raptar a su esposa, Deyanira. En la lucha, Hércules despedazará los cuernos de la cabeza del dios, de los cuales brotará la abundancia. El motivo podía ser útil a la ciudad para alabar el origen de la cornucopia tema típico de la propaganda imperial - producida por la actividad de su divinidad epónima ${ }^{4}$.

El otro cuadro, con la "Apoteosis de Hércules", muestra al héroe en el Olimpo, acompañado por las diosas Hera y Athena. La presencia de Hera es insólita, pues en la tradición iconográfica griega, el héroe aparece acompañado por Hermes y Atenea, pero en la pared del fondo aparece el arcoiris, en referencia a Júpiter. En su apoteosis, el héroe es presenta- do a Júpiter, Juno y Minerva, es decir, la Tríada Capitolina ${ }^{5}$. Se trata, entonces, de una traducción romana, única y muy interesante, de un célebre mito griego. El mensaje que comunica en este contexto es aproximadamente la idea de que también los seres humanos pueden alcanzar la perfección si consiguen las "virtutes".

En conclusión, el programa figurativo parecería haber sido concebido en tres niveles: el culto al emperador (con el busto y las estatuas), el culto del fundador Heracles, divinizado (la "apotheosis") en cuanto benefactor de la humanidad ("cornucopia"), y los "pinakia" (con los premios agonales) como alusión a las metas obtenibles por los mortales. Hércules, el héroe de origen humano, divinizado por haber superado las pruebas, bien se prestaba a preparar o a remarcar la ideología de una monarquía divina. Prueba de esto es el empleo alegórico de este personaje que todavía hacían en el siglo XVIII y XIX, las monarquías europeas, hasta los Borbones ${ }^{6}$.

\section{LA PALESTRA DE HERCULANO}

En la palestra de Herculano", la "iuventus herculanensis", una asociación de carácter

\footnotetext{
${ }^{3}$ Sobre el uso de ápices: Oliver, 1966, 129-170.

${ }^{4} \mathrm{Cfr}$. Dionisio de Halicarnaso 1, 44; Marcial, Epigr. IV 44. La asociación de la cornucopia con las figuras imperiales o de rango imperial está notablemente difundida en el mundo romano. Quizás, el ejemplo artistico más sugestivo sea el estupendo Camafeo de Viena, donde están enfrentados los bustos de dos parejas imperiales sostenidos por cornucopias, los de Germánico y Agripina Mayor (a derecha) en ocasión de las bodas de Claudio con Agripina Menor (a izquierda): Kraus, 1967, num. XIXa (a col.).
}

Ateniéndonos a la zona de Campania, en Misena, justamente en el Colegio de los Augustales se encontró recientemente una estatua idealizada de matrona de la casa julio-claudia, representada como personificación de la "Abundancia" (la estatua fue robada después del hallazgo): De Franciscis, 1991, 20s., Fig. 9. De Pozzuoli provienen, una estatua de Livia (De Franciscis, 1991, nota 8) y una de Augusto (De Franciscis, 1991, nota 9), ambas con cornucopia. También las monedas nos confirman que el motivo constituía un "topos" de la propaganda imperial, bastará citar, por ejemplo, una moneda de Calígula que presenta en el reverso a Agripina, Drusila y Julia, y una de Nerón, con Nerón, Mesalina y Popea también en su reverso, donde las mujeres llevan precisamente la cornucopia (De Franciscis, A., 1991, nota 7).

${ }^{5}$ Se advierte además cómo el héroe aparece sentado, según el célebre modelo del Heracles sentado de Lisipo, llevado a Roma y expuesto en el Capitolio: Moreno, 1987, 231ss.

6 Moreno, P., 1982, 379ss. Un precedente en época aragonesa: Adamo Muscettola, S., 1988-1989, 236-244.

7 Sobre la Palestra de Herculano: Maiuri, 1958, 136ss. Sobre las pinturas: Pappalardo, 1993a, vol. 2, nr. 443-450; Pagano, 1996, 229-248 (passim), Fig. 1-21. 


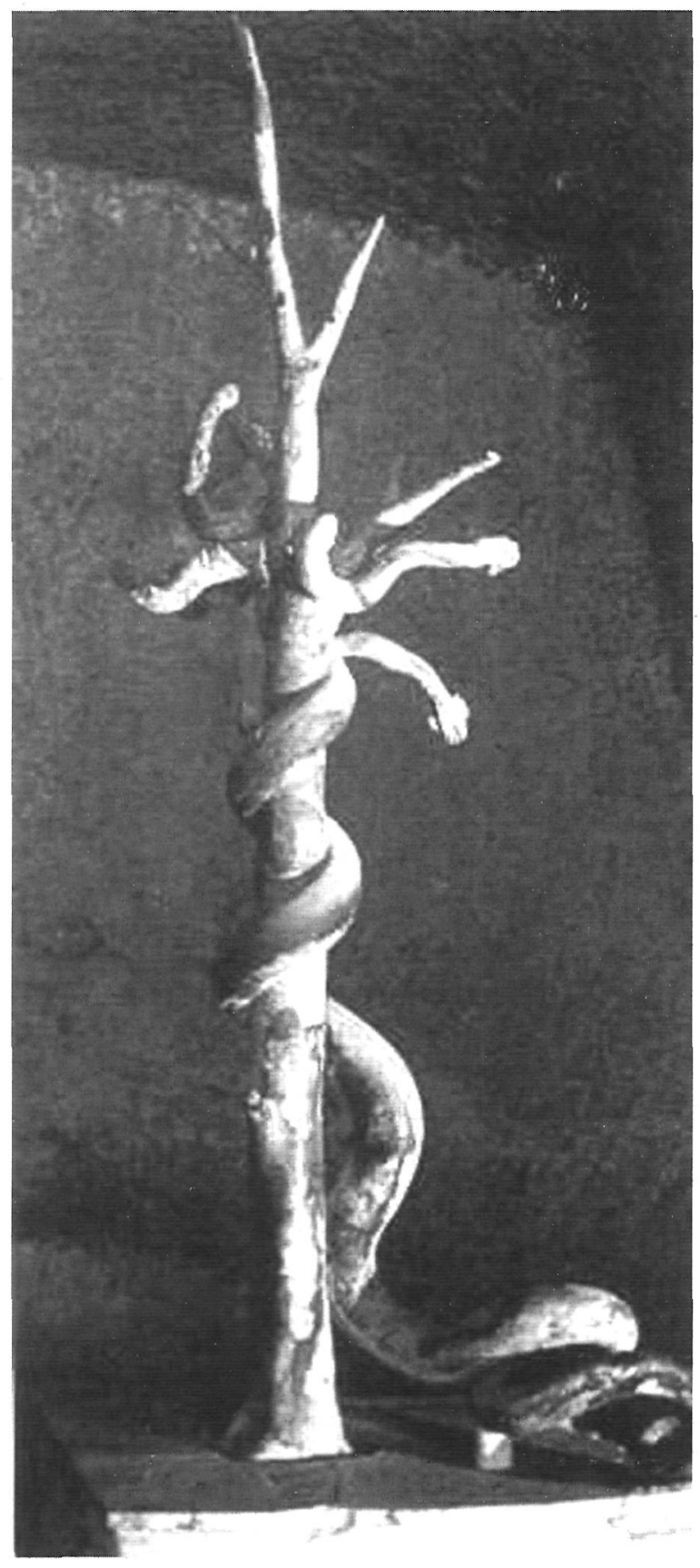

Figura 2: Herculano, Palaestra, hidra en bronce.

paramilitar, era educada con los nuevos valores de la ideología imperial ${ }^{8}$.

El edificio estaba constituido por un amplio gimnasio al aire libre, con una piscina en forma de cruz, circundada en dos de sus lados por una construcción de dos plantas. En la planta baja, de construcción julio-claudia, hay decoración pictórica en el denominado tercer estilo; mientras que la decoración en el llamado cuarto estilo testimonia una renovación de época vespasiana.

En el centro de la piscina hay una hidra en bronce (Maiuri, 1954, 193ss), aludiendo a uno de los trabajos de Hércules, que debía servir de estímulo para los jóvenes, quienes como el dios fundador, debían ejercitar la "virtus heroica" y les ayudaba a soportar el esfuerzo si deseaban ganarse los premios (Fig. 2). No era casualidad que la hidra estuviese alineada en un eje óptico con la mesa agonal, donde estaban expuestos los premios y con la estatua del emperador en el ábside central.

\section{LA BASILICA DE HERCULANO}

La Basílica de Herculano, excavada en época borbónica, aun hoy no ha sido sacada completamente a la luz ${ }^{9}$. De todos modos, conocemos la planta gracias a un diseño de Cochin y Bellicard de 1754 y aún mejor, por uno de Bardet del 1743, también tenemos una reconstrucción sugestiva aunque fantasiosa de su interior con el encargo hecho a Raffaello Morghen por Carlo Bonucci (Fig. 3).

Este edificio, al igual que el edificio de Eumachia en Pompeya, tenía en su interior un gran espacio circundado por un pórtico (Pagano, 1985, 111-121). La pared del fondo estaba modulada por ábsides y nichos rectangulares. En los ábsides había cuadros pintados con "Teseo liberador" y "Hércules y Télefo", en los nichos menores los cuadros eran de "Aquiles y Quirón" y "Pan y Olimpo".

El cuadro en que Quirón de Tesalia enseña a tocar la lira a Aquiles de Asia Menor hacía pendant con el cuadro en que Pan de Arcadia enseña a tocar la flauta a Olimpo de Asia Menor. El sentido que se desprende de esta contraposición puede ser la exaltación de la "paideia" civilizadora. Por Plinio (Naturalis Historia 36, 29) sabemos que ambos grupos estaban representados en Roma en los "Saepta Iulia”, donde también se representaban los Argonautas; en cambio, en la Basílica de Herculano, los Argonautas estaban represen-

8 Sobre la "iuventus" véase por ahora Della Corte, 1924; cfr. Castrén, 1975, 33 (con nota 1), 112, 11; Ginestet, 1991. Sobre la "iuventus" está en preparación una indagación histórica por Alejandro Bancalari (2000).

9 Sobre la Basílica de Herculano: Maiuri, 1958, 87-90; Allroggen Bedel, 1974, 97-109, in partic. 105; Allroggen Bedel, 1983, 139-158; Wohlmayr, 1989, 193-196; Najbjerg, 1997. Sobre las estatuas ecuestres de los Nonii Balbi: Zanker, 1983a, 251-256; Zanker, 1983b, 260-263 con Lám. 29-31 (Datación augustea de los ornamentos); Adamo Muscettola, 1982, 2-16; Pappalardo, 1997, 285-297, tavv. 5968. Sobre las pinturas: Pappalardo, 1993a, vol. 2, nr. 451453. 


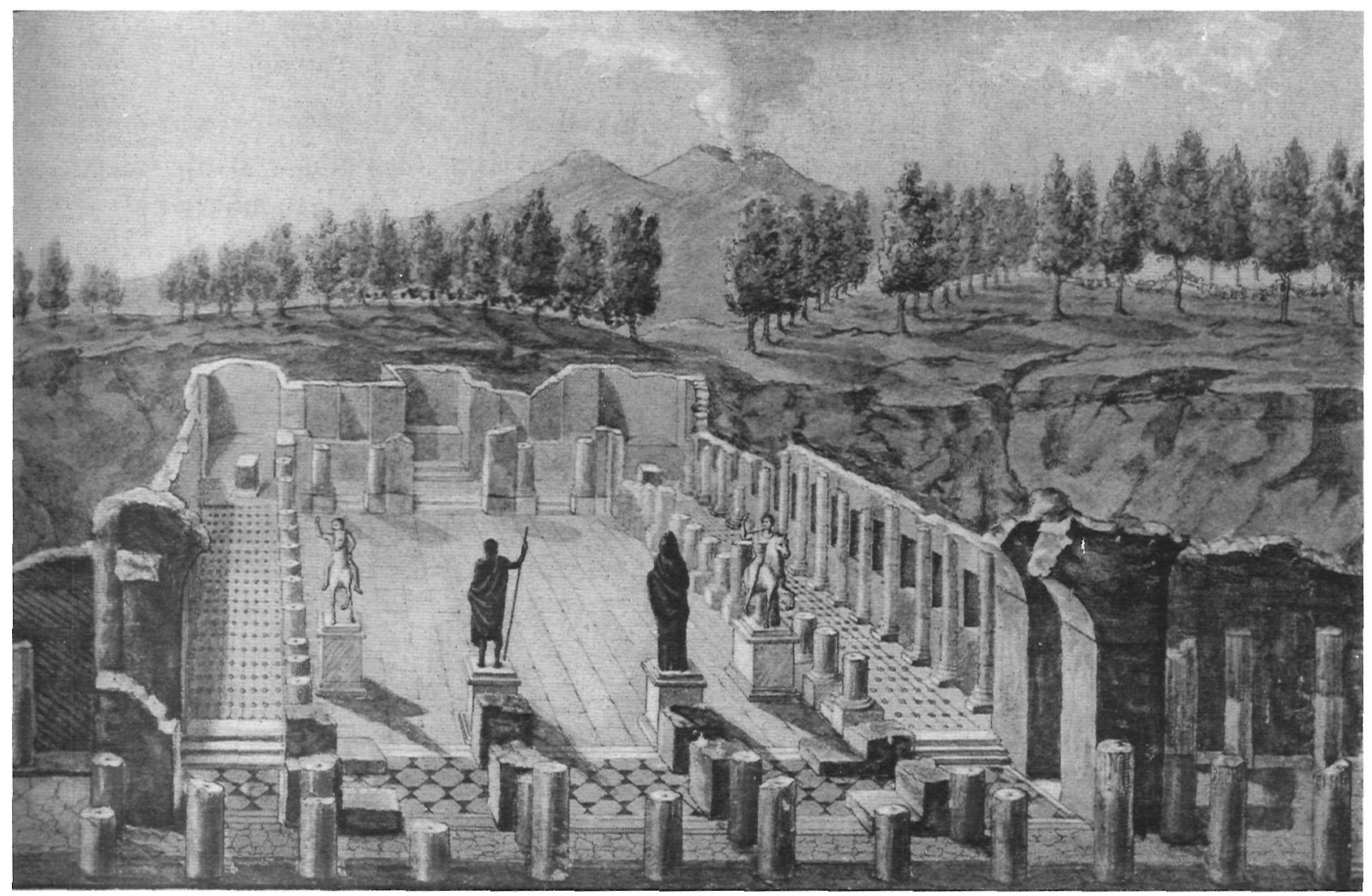

Figura 3: Herculano, Basílica, reconstrucción de Carlo Bonucci y Raffaello Morghen (1835).

tados por Medea que planea el asesinato de sus hijos tenidos con Jasón. De este modo, se establece una conexión entre el edificio de Herculano y los "Saepta" de la Urbe. También estaban dispuestos en pendant los otros dos cuadros, el de Hércules y Télefo y el de Teseo.

En este caso, la disposición tiene como objetivo una intencional multiplicidad de significados: Hércules, el fundador de Herculano, es el padre de Télefo, el sobreviviente de la dinastía real de Pérgamo. Télefo fue criado por una pequeña cierva, así como Rómulo lo fue por una loba. Rómulo, fundador de Roma, es a su vez, también el homólogo de Teseo, fundador de Atenas, y por este motivo Plutarco los pone juntos en sus "Vidas Paralelas". La deducción de estos silogismos parecería ser: Roma es la heredera de Pérgamo y la nueva Atenas (La Penna, 1974).

\section{EL EDIFICIO DE EUMACHIA EN POMPEYA}

Romulus, Martis / filius, urbem Romam [condi]dit, et regnavit annos / duodequadraginta. Isque / primus dux, duce hostium Acrone rege Caeninensium / interfecto, spolia opi[ma] / lovi Feretrio consecra[vit]; /receptusque in deoru[m] Inumerum, Quirinu[s] appellatu[s est - - -]
"Romulo, hijo de Marte fundó la ciudad de Roma y reinó treinta y ocho años. El, primer comandante, después de haber matado al jefe de los enemigos, Acrón rey de los cenineses, consagró los despojos opimos a Júpiter Feretrio; aceptado en el número de los dioses, fue llamado Quirino".

Esta inscripción ${ }^{10}$ apareció debajo de uno de los cuatro nichos de la fachada del llamado Edificio de Eumachia en Pompeya, un mercado de la lana que daba al Foro de la ciudad $(\text { Fig. } 4)^{11}$. No muy lejos aparecieron fragmen-

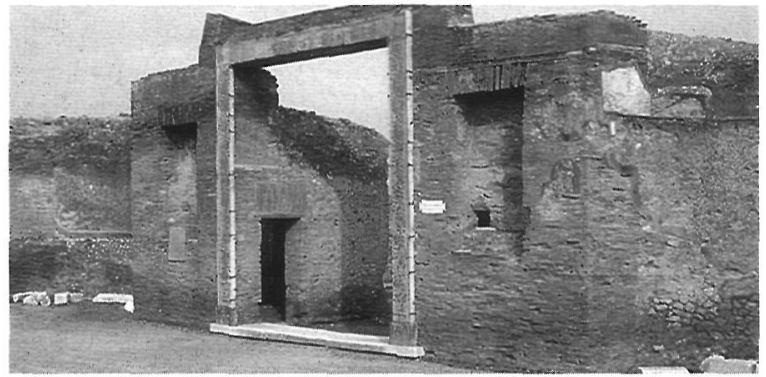

Figura 4: Pompeya, Edificio de Eumachia.

${ }^{10}$ CIL X, 809; traducción de Onorato, 1957, 74s., $n^{\circ} 83$ con nota en 149 .

11 Sobre el Edificio de Eumachia en Pompeya: Spano, 1961, 5-35; Coarelli, La Rocca, y De Vos, 1980, 114-118; Zanker, 1993, 105-112. 


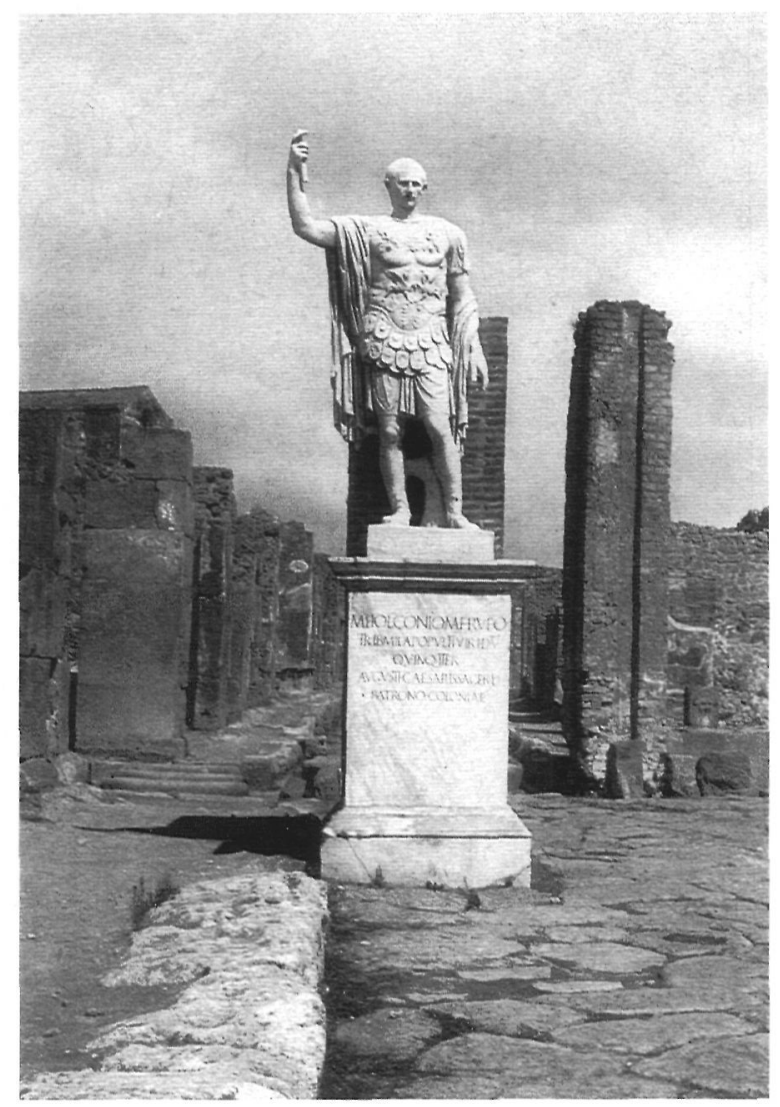

Figura 5: Pompeya, Via de la Abundancia, estatua honorífica de Marco Holconio Rufo.

tos del "elogium" de Eneas. Además de las estatuas de Eneas y Rómulo, en los otros nichos de la fachada debían estar las estatuas de César y Augusto. El hecho de que cada columna tuviese adosada el basamento de una estatua nos sugiere la hipótesis de que se tratase de una verdadera galería, casi una cita de la galería de los "summi viri" en el Foro de Augusto en Roma.

¿Qué sentido tenían estos "elogia" en un edificio comercial? La idea era transformar la fachada en un propio y verdadero monumento celebrativo de la dinastia Julia, decorándola con las estatuas de sus antepasados y sus correspondientes "elogia".

¿Quién fue el artífice de esta exaltación? La dueña del edificio, Eumachia, pertenecía a una rica familia de antigüo origen campano y quizás ya griego, que debía su riqueza a la viticultura y a la producción de ánforas (Castrén, 1975, 71, 94s., 101, 165s.). Eumachia se había casado con un descendiente de la noble familia de los Numistrii y a la muerte de su esposo heredó una gran empresa comercial dedicada a la industria de la lana. Por lo tanto, de su persona pasaron a depender numerosas actividades productivas. La corporación de ven- dedores de telas la reconocía como su patrona y le dedicó una estatua en el gran mercado. Además fue declarada sacerdotisa de Venus, la diosa más importante de la ciudad precisamente denominada "Colonia Cornelia Veneria Pompeia.

\section{LA ESTATUA DE MARCUS HOLCONIUS RUFUS EN POMPEYA}

Los Pompeyanos le dedicaron a Marco Holconio Rufo una estatua honorífica en la Via de la Abundancia, una de las calles comerciales más transitada de la ciudad (Fig. 5) ${ }^{12}$. Este personaje descendia de una de las familias que producían un apreciado vino. Inició su carrera política aproximadamente en el 20 a.C. y se convirtió en el personaje político de mayor notoriedad en Pompeya durante la época augustea (Castrén, 1975, 68s., 97, 104, 176). Fue elegido duumviro cuatro veces, fue "sacerdos Augusti" y el emperador le otorgó el título excepcional de "tribunus militum a populo".

La estatua que la municipalidad le dedicó por sus méritos nos lo muestra con la distinción recibida, con la armadura del "tribunus militum", bajo la cual lleva puesto el calzado alto propio de los senadores (calceoli); de hecho, pertenecía en realidad a la clase de los caballeros, la máxima categoria representada en Pompeya; mientras que el tipo de estatua escogido por él imita la de Mars Ultor en el Foro de Augusto en Roma.

\section{IMITACIÓN DEL “PRINCEPS”EN EL RETRA- TO BURGUÉS}

Manifestar la adhesión a la ideología del "princeps" se convirtió en un tema obsesivo para la burguesía, al extremo que esta adhesión se manifiesta hasta en detalles ingenuos, por ejemplo, la frecuente imitación del peinado con los mechones sobre la frente dispuestos "a modo de tenaza" ${ }^{13}$, como lo muestra un retrato de una pareja en una pintura en Stabia (Fig. 6) ${ }^{14}$.

\footnotetext{
12 Sobre la estatua de Marco Holconio Rufo en Pompeya: Zanker, 1981, 349-361; Zanker, 1993.

13 Influencia del retrato de Augusto en el retrato burgués: Zanker, 1982, 307-312, fig. 197-209; Pappalardo, 1991 (Apéndice); Pappalardo, 1995, 413-415.

${ }^{14}$ Castellammare, Antiquarium $n^{\circ} 4179$; da Stabia, Villa di Varano, "Ritratto di coppia in rombo": Miniero, 1989, $42 \mathrm{n}^{\circ} 3$; Pappalardo, 1993a, vol. I, lám. a col. 168; vol. II, n 487.
} 


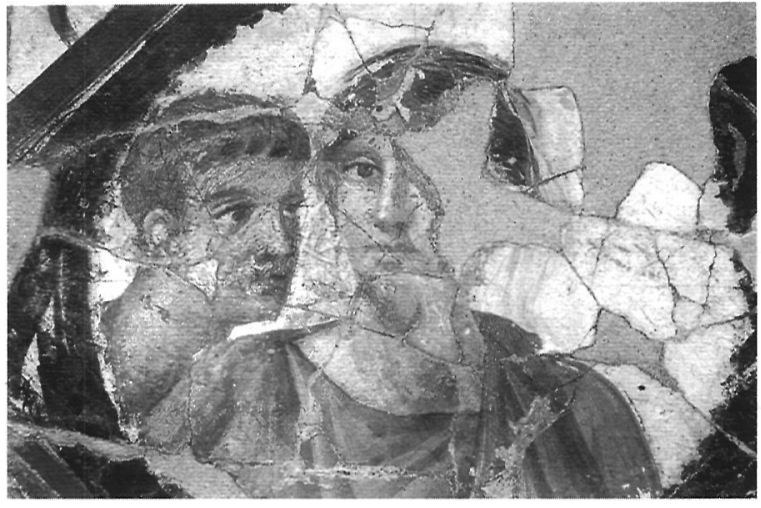

Figura 6: Stabia, pintura con pareja.

\section{CONCLUSIÓN}

Podríamos continuar citando ejemplos de Pompeya, como el Templo de la Fortuna Augusta, la Palestra etc., pero no es una lista de casos lo que nos interesa en esta cuestión. Lo importante es la constatación de que casi toda la actividad edilicia pública, tanto en Pompeya como en Herculano, después del 20 a.C., dependía directamente e indirectamente de la instauración de la monarquía por César Augusto.

De hecho, después del caos de fines de la república, luego de tres décadas de guerras sociales, de proscripciones y expropiaciones, finalmente la "pax augusta" traía la estabilidad y la seguridad, y con éstas, un gran renacimiento económico.

En las ciudades itálicas, sean los casos puntuales de Pompeya y Herculano, así como en el resto de las provincias occidentales, fueron las familias más influyentes y los "parvenus" quienes se identificaron con el programa cultural del nuevo régimen y con la ideología del "princeps", transmitiendo este modelo a sus propios conciudadanos, como si éste fuese el ejemplo supremo a imitar, de todas las "virtutes", tanto humanas como civiles y religiosas (Zanker, 1983a, 266; idem, 1982, 307312, fig. 197-209).

\section{(Traducción: Susana G. Guglielmino, Buenos Aires)}

Prof. Umberto Pappalardo

Istituto Universitario «Suor Orsala Benincasa»

Via Suor Orsola Benincasa

Corso Vittorio Emanuele, 292

80135 Nápoles (Italia)

umbpappa@unina.it

\section{BIBLIOGRAFIA}

AA.VV., 1980: Bilder vom Menschen in der Kunst des Abendlandes, Berlin (Staatliche Museen).

ADAMO MUSCETTOLA, S., 1982: "Nuove letture borboniche. I Nonii Balbi ed il Foro di Ercolano", Prospettiva, 28, 2-16.

ADAMO MUSCETTOLA, S., 1988/89: "Memorie ritrovate di Napoli antica", Scritti in ricordo di Giovanni Previtali, vol. 1 = Prospettiva, 53/56, 236-244.

ALLROGGEN BEDEL, A., 1974: "Das sogenannte Forum von Herculaneum und die bourbonischen Grabungen von 1739", Cronache Ercolanesi, 4, 97-109.

ALLROGGEN BEDEL, A., 1983: "Dokumente des 18. Jahrhunderts zur Topographie von Herculaneum" , Cronache Ercolanesi, 13, 139-158.

ANDREAE, B., 1973: Römische Kunst, Freiburg.

BANCALARI MOLINA, A., 2000: "El Emperador Augusto y las asociaciones juveniles: significación y difusión", Revista de Estudios Clásicos, 29, 39-53.

CASTRÉN, P., 1975: Ordo populusque pompeianus. Polity and Society in Roman Pompeii (= Acta Instituti Romani Finlandiae nr. 8), Roma.

COARELLI, F., y LA ROCCA, E., y de VOS, M., 1980: Guida archeologica di Pompei, Milano.

De FRANCISCIS A., 1991: / Sacello degli Augustali a Miseno, Napoli.

DELLA CORTE, M., 1924: Iuventus, Arpino.

DUTHOY, R., 1978: "Les Augustales", Aufstieg und Niedergang der Römischen Welt (= ANRW) II, 16, 2, Berlin, 1254-1309

ETIENNE, R., 1993: "À propos du cosidetto édifice des Augustales d'Herculanum", Franchi dell'Orto, L. (Dir.): Ercolano 1738-1988. 250 anni di ricerca archeologica, Atti Convegno Internazionale Ravello- Ercolano Napoli Pompei 30.X-5.XI 1988, 345-350, Roma.

FEDELI, P., 1991: Introduzione a Catullo, Bari-Roma.

GINESTET, P., 1991: Les organisations de la jeunesse dans l'Occident romain, Bruxelles.

GUADAGNO, G., 1983: "Herculanensium Augustalium Aedes", Cronache Ercolanesi, 13, 1983, 159-173.

GUADAGNO, G., 1977: "Frammenti inediti di Albi degli Augustali", Cronache Ercolanesi, 7, 114-122.

GUADAGNO, G., 1988: "I graffiti della Aedes Augustalium. Documenti sull'accesso all'augustalità”, Cronache Ercolanesi, 18, 199-203.

KRAUS, T., 1967: Das römische Weltreich (= Propyläen Kunstgeschichte, vol. 2).

LA PENNA, A., 1974: Orazio e l'ideologia del principato, Torino.

MAIURI, A., 1954: "Fontana monumentale in bronzo nei Nuovi Scavi di Ercolano", Bollettino d'Arte, 3, 193 ss.

MAIURI, A., 1958: Ercolano. I Nuovi Scavi 1938-1958, Roma.

MINIERO, P., 1989: Stabiae. Pitture e stucchi delle ville romane, Napoli.

MOORMANN, E., 1983: "Sulle pitture dell'Herculanensium Augustalium Aedes", Cronache Ercolanesi, 13, 175-177.

MORENO, P., 1987: Vita e arte di Lisippo, Milano.

MORENO, P., 1982: "Il Farnese ritrovato ed altri tipi di Eracle a riposo", MEFRA, 94, 1, 379ss.

NAJBJERG, T., 1997: Public painted and sculptural programs of the early Roman Empire. The case study of the socalled Basilica in Herculaneum, Diss. Princeton.

NORBERG, D., 1946: “La divinité d'Auguste dans la poèsie d'Horace", Eranos, 389ss.

OLIVER, R. O., 1966: "Apex and Sicilicus", American Journal of Philology, 87, 129-170. 
ONORATO, G.O., 1957: Iscrizioni pompeiane, Firenze.

PAGANO, M., 1985: "Note sui macella nel mondo romano", Rendiconti Napoli, 59, (1984), 111-121.

PAGANO, M., 1996: "La nuova pianta della città e alcuni edifici pubblici di Ercolano", Cronache Ercolanesi, 26, 229-248.

PAPPALARDO, U., 1991: "Il ritratto romano dipinto", Galasso, G., y Vallet, G., (Ed.), Storia del Mezzogiorno, vol. 1, 2, Napoli.

PAPPALARDO, U., 1993a: en: AA.VV., La peinture de Pompéi, vol. 2, Paris (Hazan).

PAPPALARDO, U., 1993b: "Spazio sacro e spazio profano: il Collegio degli Augustali di Ercolano", Moormann, E. (Ed.): Functional and Spatial Analysis of Wall Painting. Proceedings of the Fifth International Congress on Ancient Wall Painting, Universiteit van Amsterdam 812.IX.1992, Bulletin Antieke Beschaving (BABesch), Suppl. 3, 90-95, Leiden.

PAPPALARDO, U., 1995: "El retrato en la pintura romana", Lavagne, H. (Ed.), Jeunesse de la Beauté. La peinture romaine antique. Mostra Paris, 413-415, Union Latine, Parigi.

PAPPALARDO, U., 1997: "Nuove testimonianze su Marco Nonio Balbo ad Ercolano", Mitteilungen des Deutschen Archäologischen Instituts Rom, 104, 285-297.

ROSTOVZEV, M., 1981: Storia economica e sociale dell'Impero Romano, Firenze.
SPANO, G., 1961: "L'Edificio di Eumachia in Pompei", Rendiconti Napoli, n.s. 36, 5-35.

WOHLMAYR, P., 1989: "Überlegungen zur Basilika von Herculaneum", Akten des 3. Österreichischen Archäologentages, 193-196, Wien.

ZANKER, P., 1981: "Das Bildnis des M. Holconius Rufus", Archäologischer Anzeiger, 349-361.

ZANKER, P., 1982:"Herrscherbild und Zeitgesicht", Wissenschaftliche Zeitschrift der Humboldt-Universität Berlin, Geschichte-Sprachwissenschaft, 31, 2/3, 307-312.

ZANKER, P., 1983 a: "Zur Bildnisrepräsentation führenden Männer", Les bourgioisies municipales italiennes. Colloquio Centre Jean Bérard, Napoli 7-10.XII.1981, 251256, Napoli.

ZANKER, P., 1983 b: "Die Statuen des M. Nonius Balbus und seiner Familie", Les bourgioisies municipales italiennes. Colloquio Centre Jean Bérard, Napoli 7-10.XII.1981, 260-263, Napoli.

ZANKER, P., 1987: Augustus und die Macht der Bilder, München [trad.ital.: Augusto e il potere delle immagini, Torino, 1989].

ZANKER, P., 1991: "Immagini e valori collettivi", Momigliano, A. y Schiavone, A., (Dirs.), Storia di Roma, vol. II, 2: "L'Impero mediterraneo. I principi e il mondo" , 193-220, Torino.

ZANKER, P., 1993: Pompei. Società, immagini urbane e forme dell'abitare, Torino. 